\title{
Using Dimmable Lighting for Regulation Capacity and Non-Spinning Reserves in the Ancillary Services Market A Feasibility Study
}

Francis Rubinstein, Li Xiaolei, David S. Watson Lawrence Berkeley National Laboratory

December 2010 


\section{Disclaimer}

This document was prepared as an account of work sponsored by the United States Government. While this document is believed to contain correct information, neither the United States Government nor any agency thereof, nor The Regents of the University of California, nor any of their employees, makes any warranty, express or implied, or assumes any legal responsibility for the accuracy, completeness, or usefulness of any information, apparatus, product, or process disclosed, or represents that its use would not infringe privately owned rights. Reference herein to any specific commercial product, process, or service by its trade name, trademark, manufacturer, or otherwise, does not necessarily constitute or imply its endorsement, recommendation, or favoring by the United States Government or any agency thereof, or The Regents of the University of California. The views and opinions of authors expressed herein do not necessarily state or reflect those of the United States Government or any agency thereof or The Regents of the University of California. 


\section{Acknowledgements}

The work described in this report was supported by the Demand Response Research Center and funded by the California Energy Commission, Public Interest Energy Research (PIER) program, under Work For Others Contract No. 500-03-026 and by the U.S. Department of Energy under Contract No. DE-AC02-05CH11231. The authors would like to thank former Energy Commissioner Art Rosenfeld, who originally challenged us to explore the use of dimmable lighting for providing regulation reserves in the State. We also thank Joe Eto, who encouraged us to do the feasibility study and to Ron Hoffman who helped correct our misconceptions along the way. Finally, we would like to thank Mary Ann Piette for her patient support of this work.

Please cite this report as follows:

Rubinstein, F., L. Xiaolei, D.S. Watson. (2010). Using Dimmable Lighting for Regulation Capacity and Contingency Reserves in the Ancillary Services Market. A Feasibility Study. PIER Buildings EndUse Energy Efficiency Program. CEC-500-xxxx-xxx. 


\section{Table of Contents}

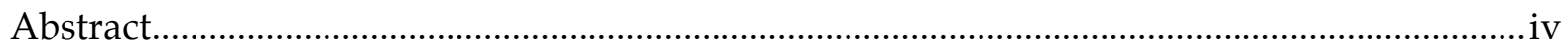

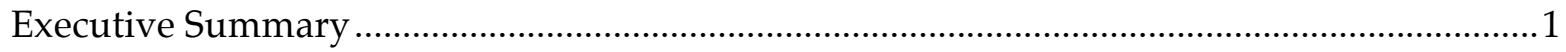

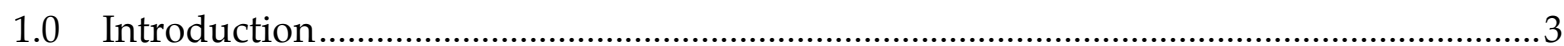

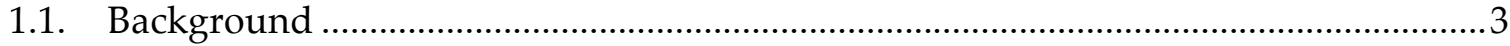

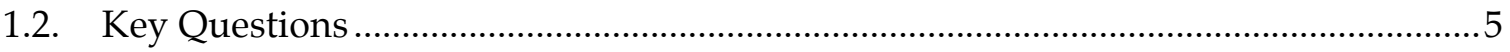

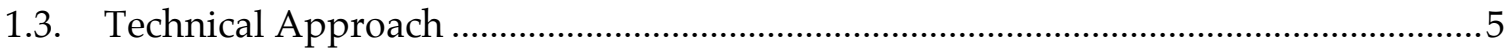

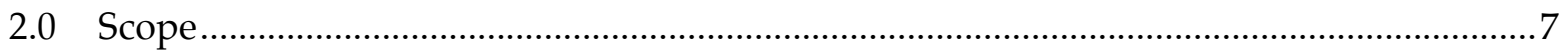

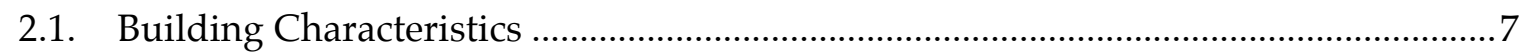

2.1.1. Total Floor Space By Building Size Category …................................................

2.1.2. Number of U.S. Buildings By Building Size Category ........................................ 8

2.1.3. Technical Potential for Regulation Capacity and Contingency Reserves...........9

2.1.4. Economic Potential for Regulation Capacity and Contingency Reserves ..........11

2.2. Number of Potential New Ancillary Services Accounts............................................14

2.3. Dimmable Lighting Characteristics ........................................................................... 15

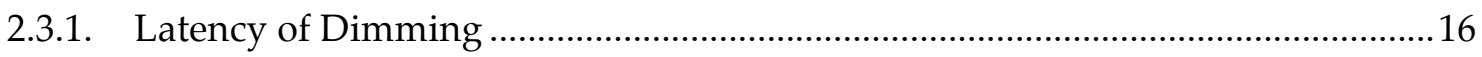

2.4. Total Statewide Potential for Dimmable Lighting.....................................................16

2.5. Types of Lighting Controls ................................................................................. 17

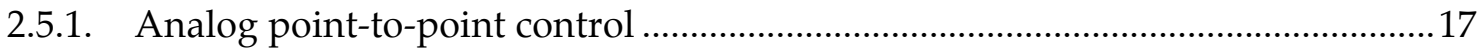

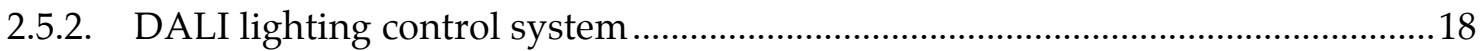

3.0 CAISO Technical Requirements ................................................................................... 19

3.1. Current Regulation Up and Regulation Down Requirements ..................................19

3.2. Current Spinning Reserve Requirements ..............................................................19

3.3. Current Non-Spinning Reserve Requirements ............................................................19

3.4. Proposed Changes to ISO Requirements .................................................................20

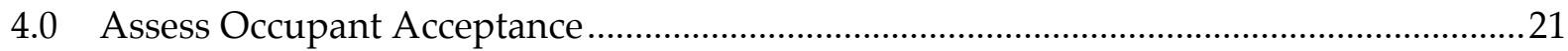

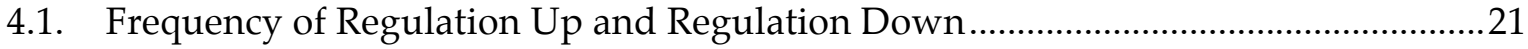

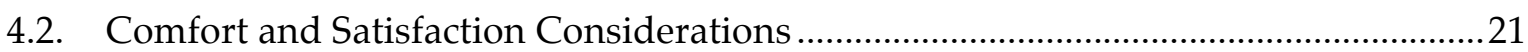

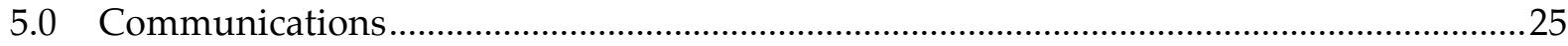

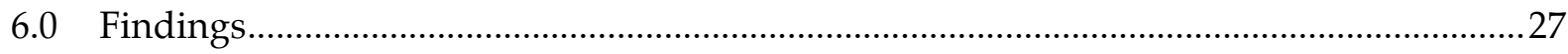

7.0 Conclusions, Recommendations, \& Benefits to California ...............................................29

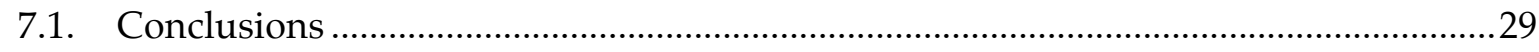

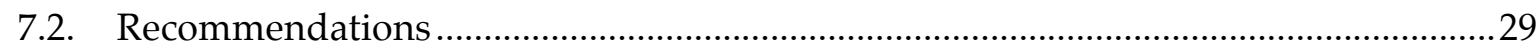

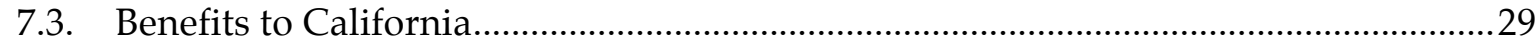

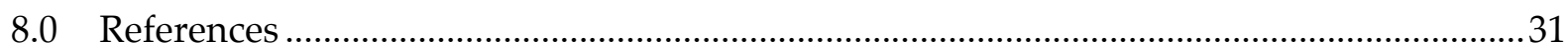

9.0 Glossary 


\section{List of Figures}

Figure 1. The CAISO total demand response market for 2007 broken down according to ancillary service provided.

Figure 2. The total area of the U.S. commercial building inventory, classified according to building size......

Figure 3. The total number of U.S. commercial buildings, classified according to building size category.

Figure 4. The estimated Statewide potential for regulation capacity and contingency reserve capacity broken down according to large $(>50,000 \mathrm{sf})$ buildings and small buildings $(<=$ $50,000 \mathrm{sf})$.

Figure 5. The estimated Statewide potential for regulation capacity and contingency reserve capacity broken down according to eight building size categories.

Figure 6. Assumed user compliance plotted against power reduction requested (as \% of maximum power)

Figure 7. Typical input power, light output curve for a modern fluorescent dimming ballast. ...15

Figure 8. Generic network diagram for controlling individual analog dimming ballasts from a digital network.

Figure 9. Generic network diagram for a DALI lighting control system .18

Figure 10. Different light level fluctuations presented to test subjects to assess occupant acceptability of varying light levels.

Figure 11. Fraction of subjects noticing different electric lighting reductions in daylighted and non-daylighted spaces.

Figure 12. Fraction of people accepting different electric light level reduction in daylighted and non-daylight spaces. .24

Figure 13. Demand Response control packet latency between software client and demand response automation server (DRAS) across the public Internet in Northern CA. .26

\section{List of Tables}

Table 1. Economic Potential of Contingency Reserve from Dimmable Lighting in Large Commercial Buildings for Three Market Penetration Scenarios.

Table 2. Number of California Commercial Buildings in Different Size Categories and Estimate

Number of Accounts 


\begin{abstract}
The objective of this Feasibility Study was to identify the potential of dimmable lighting for providing regulation capacity and contingency reserves if massively-deployed throughout the State. We found that one half of the total electric lighting load in the California commercial sector is bottled up in larger buildings that are greater an 50,000 square feet. Retrofitting large California buildings with dimmable lighting to enable fast DR lighting would require an investment of about $\$ 1.8$ billion and a "fleet" of about 56 million dimming ballasts. By upgrading the existing installed base of lighting and controls (primarily in large commercial facilities) a substantial amount of ancillary services could be provided. Though not widely deployed, today's state-of-the art lighting systems, control systems and communication networks could be used for this application. The same lighting control equipment that is appropriate for fast DR is also appropriate for achieving energy efficiency with lighting on a daily basis. Thus fast DR can leverage the capabilities that are provided by a conventional dimming lighting control system. If dimmable lighting were massively deployed throughout large California buildings (because mandated by law, for example) dimmable lighting could realistically supply $380 \mathrm{MW}$ of non-spinning reserve, $47 \%$ of the total non-spinning reserves needed in 2007.
\end{abstract}

Keywords: demand response, dimmable lighting controls, ancillary services, regulation capacity, contingency reserves, dimming ballasts 


\section{Executive Summary}

The objective of this Feasibility Study is to identify the potential of dimmable lighting for providing regulation capacity and contingency reserves if massively-deployed throughout the State. We first use available data on U.S. buildings to characterize the total square footage of U.S. commercial building stock according to building size, shape, and number of floors. Second, we use technical performance data for dimmable ballasts to estimate the demand reduction potential per ballast for regulation capacity and contingency reserve while maintaining acceptable levels of occupant lighting service. We then estimate the number of California buildings that could potentially use dimmable lighting for regulation capacity and contingency reserves.

These are the findings of the Feasibility Study:

1. Roughly one half of the total electric lighting load in the California commercial sector is bottled up in larger buildings that are greater than 50,000 square feet. There are roughly 25,000 large commercial buildings in the State that are in this size category, constituting about 3.6 billion square feet of floor space in California.

2. Retrofitting large California buildings with dimmable lighting to enable fast DR lighting (and other control strategies) would require an investment of about $\$ 1.8$ billion and would require a "fleet" of about 56 million dimming ballasts.

3. By upgrading the existing installed base of lighting and controls (primarily in large commercial facilities) a substantial amount of ancillary services could be provided. Though not widely deployed, today's state-of-the art lighting systems, control systems and communication networks could be used for this application. There are no technically insurmountable barriers to providing such an infrastructure.

4. The same lighting control equipment that is appropriate for fast DR is also appropriate for achieving energy efficiency with lighting on a daily basis. Thus fast DR can leverage the capabilities that are provided by a conventional dimming lighting control system.

5. Assuming that each dimming ballast can be ramped up or down by 4 watts from a nominal $80 \%$ operating level, there is about $450 \mathrm{MW}$ of regulation up or regulation down capacity available throughout large California buildings. This is more than the entire ISO requirement for regulation reserves for the year of 2007.

6. Assuming that each dimming ballast can be ramped down from full power to $25 \%$ power, the technical potential is $2.5 \mathrm{GW}$ of non-spinning reserve capacity available throughout large California buildings. The economic potential of dimmable lighting for contingency reserves is less due to market forces and economics.

7. If dimmable lighting were massively deployed throughout large California buildings (because mandated by law, for example) dimmable lighting could supply $380 \mathrm{MW}$ of contingency reserve, $47 \%$ of the total contingency reserves needed in 2007. 


\subsection{Introduction}

The purpose of this report is to explore the feasibility of using dimmable lighting to provide ancillary services (A/S) such as regulation capacity and contingency reserves that supplement and reduce the burden on the large generators that currently provide all ancillary services.

\subsection{Background}

In order to meet the State's electricity needs, the CAISO must adjust the balance between the generation of power and consumption (load) at several time scales. The CAISO procures regulation capacity, spinning and non-spinning reserves, in order to maintain exact balance of generation and demand load at the regional level. The ISO has three methods to match generation and load:

1. "Load following" is based on advance-scheduling of power generation according to predicted load. These resources are bid into the day-ahead or day-of markets. Most "reliability-based" Demand Response programs fall into this category.

2. Spinning and non-spinning reserves ${ }^{1}$ provide generation resources that can be brought on line to a specified level within 10 minutes and be maintained that way for two hours. This is similar to a "coarse" adjustment of the grid. (Spinning reserves must be able to begin ramping up immediately when called, while non-spinning reserves have 10 minutes).

3. Regulation capacity is generation that is on-line, and synchronized with the ISO so that the energy generated can be increased or decreased instantly through automatic generation control (AGC). Regulation capacity acts as a "fine" adjustment of the grid. There are separate markets for "regulation up" and "regulation down."

Any mismatch between generation and supply will cause the grid frequency to deviate unacceptably from nominal $60 \mathrm{~Hz}$. The CAISO has detailed technical requirements for regulation capacity providers (CAISO 2007). At the present time, only large generators (particularly hydro-electric) provide all the State's spinning reserves and regulation capacity needs. Non-generating customers who have sheddable load on hand to bid into the market (i.e., demand response providers) can only participate in reliability-based DR programs, not spinning reserve or regulation capacity. (Curtailable demand can also supply Contingency Reserve provided that it is telemetered and capable of receiving dispatch instructions and performing accordingly within 10 minutes.)

The CAISO total demand response market for 2007 is given in Figure 1. While the IOUs project that they already have 1,300 MW of reliability-based DR available with more in the pipeline, the CAISO has determined that the State needs only 500 - 1,000 MW of reliability DR (CAISO 2007). Because of this perceived surplus for reliability-based DR, the CAISO is encouraging projects that would allow non-generators (i.e. controllable loads) to bid into the other ancillary services market, such as regulation capacity and spinning and non-spinning reserve markets (CAISO

\footnotetext{
${ }^{1}$ Non-spinning and spinning reserves are collectively termed "contingency reserves". In this report we use the expression "contingency reserves" except in cases where it is necessary to distinguish between "spinning" and "non-spinning" reserves.
} 
2007). Note that in 2007, the total ancillary services market exceeded 2,450 MW; more than 1 GW over the State's currently available reliability-based DR.

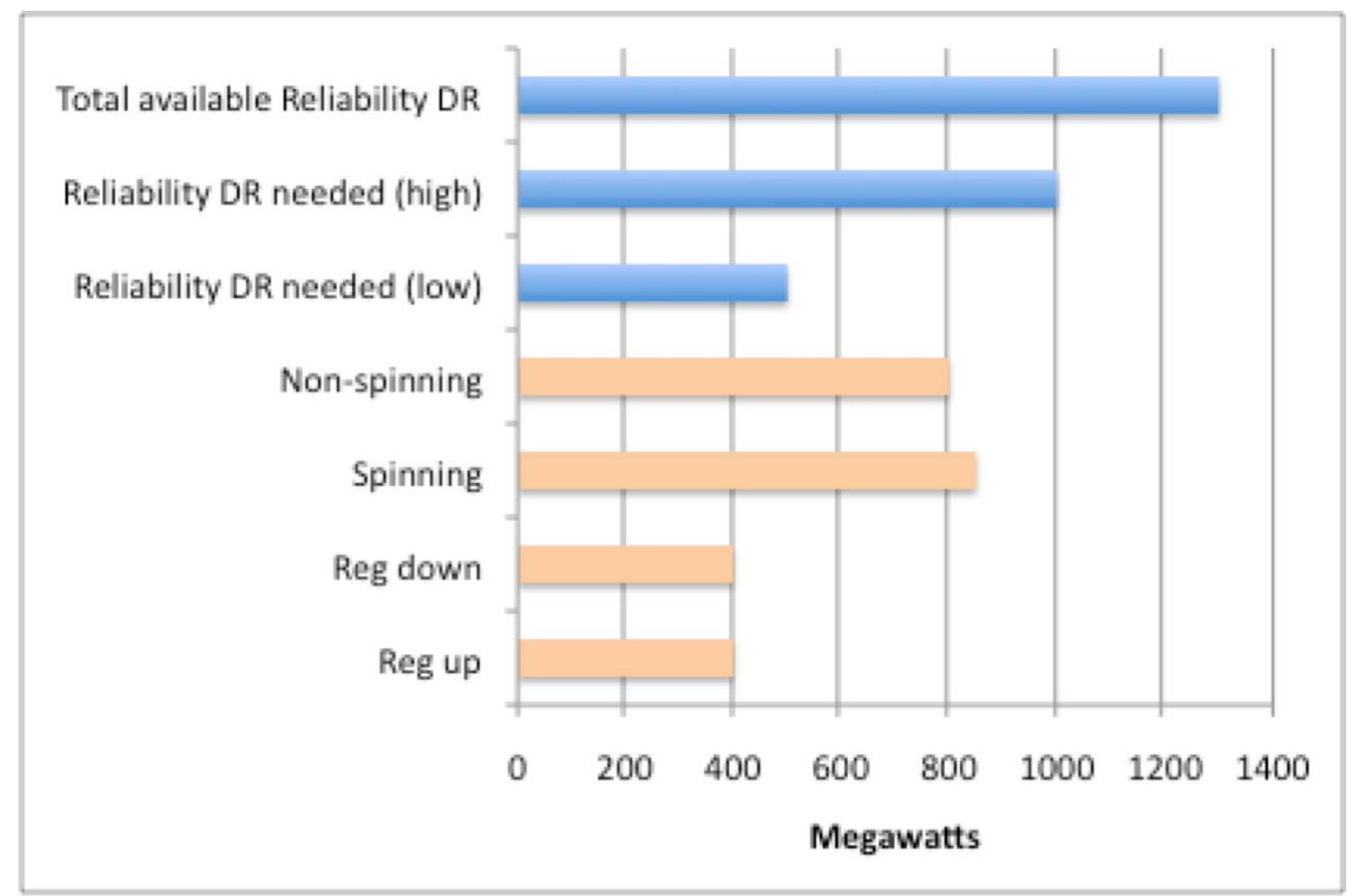

\section{Figure 1. The CAISO total demand response market for 2007 broken down according to ancillary service provided.}

In Eto et al (2007), it is argued that providing spinning reserves using demand-side resources is equivalent to providing these services using (supply-side) generators. Indeed, supplementing generation with demand-side resources would greatly increase the amount of contingency reserves available to the system operator.

In Eto et al (2007), Eto identifies three critical issues that currently impede the use of demandside curtailment for providing ancillary services in general ${ }^{2}$.

1. Current reliability rules do not consider the use of demand-side resources (controllable loads) for ancillary services because the rules were originally written considering only supply-side resources (i.e., large generators).

2. System operators do not have experience or confidence that ancillary services using controllable loads will be as reliable or effective as providing it with generators.

\footnotetext{
${ }^{2}$ Although Eto only addresses spinning reserve explicitly, the same arguments hold for non-spinning reserves and regulation capacity.
} 
3. Market rules related to aggregation, metering, and load verification don't address using aggregated demand-side resources to participate in the ancillary services market.

At present, the ISO meets its ancillary services requirements using generation assets, such as hydro-electric generation and thermal plants. This research suggests that the ISO could diversify its reserve market if it could reliably obtain small reductions from many distributed loads throughout the region to add to the generation assets that are currently obtained from hydro-electric generators. This would beneficially reduce the ISO's dependence on thermal plants for regulation capacity and spinning reserve. Thermal plants are more polluting and slow in responding to the ISO's near instantaneous signaling.

Furthermore, increased use of fast DR techniques Statewide should increase the supply of A/S offered into competitive markets leading to lower prices and increased competitiveness of these markets.

\subsection{Key Questions}

Using dimmable lighting for regulation capacity is technically challenging for several reasons. This feasibility study is intended to address the following key concerns:

- Since each dimmable ballast draws only 60 watts, millions of individual lights would have to be quickly controlled in unison to be effective for regulation capacity. How should lights be grouped into controllable "blocks" in order to be most manageable, economical etc.?

- Huge numbers of dimmable lights must be physically interfaced to the ISO at a relatively small number of logical connection points.

- The ISO's need for regulation up and regulation down can oscillate back and forth dozens, if not hundreds, of times per day. From a lighting service standpoint, these oscillations would cause variations in light level many times per hour. Occupant acceptability must be maintained.

- The ISO telemetry requires a time response from the controller on the order of 4 seconds (CAISO 1999). By no means insurmountable, it will be technically challenging to communicate with so many loads simultaneously, quickly and reliability. Internet or wireless communications are likely candidates for these communications.

\subsection{Technical Approach}

This feasibility study is the first step toward addressing these challenges:

- Current scope

Produce a feasibility study that investigates using fast-response dimmable lighting for providing regulation capacity and spinning reserves.

- Future scope

Implement a pilot study of dimmable lighting for regulation capacity at UC San Diego or in the Edison service territory.

This report is divided into five tasks as follows:

Task 1. Scope 
Objective: Identify the total potential of dimmable lighting for providing regulation capacity and spinning/non-spinning reserves throughout the State.

Task 2. Determine the CAISO technical requirements

Objective: Determine the CAISO technical requirements for regulation capacity and spinning reserves, with respect to latency, reliability and ramp rate.

Task 3. Assess occupant acceptance

Objective: To identify any negative occupant response and identify mitigation measures.

Task 4. Communications

Objective: Explore the technical challenge of controlling millions of tiny loads in unison very quickly ( 10 seconds). 


\subsection{Scope}

The objective of this task is to identify the total potential of dimmable lighting for providing regulation capacity and spinning/non-spinning reserves throughout the State. We first use available data on U.S. building characteristics to characterize the total square footage of U.S. commercial building stock according to building size, shape, and number of floors. Second, we use technical performance data for dimmable ballasts to estimate the demand reduction potential per ballast for regulation capacity and contingency reserve. We then estimate the number of California buildings that could potentially use dimmable lighting for regulation capacity and contingency reserves.

\subsection{Building Characteristics}

Previous work (Rubinstein and Kiliccote 2007) has shown that while there is great potential to save energy and reduce demand using dimmable lighting, the number of buildings that actually employ dimming ballasts is quite small (1-2\%). Nonetheless, we can get an estimate of the total potential by investigating key building parameters and computing what the potential would be if dimming ballasts were installed universally throughout the California commercial building stock.

Detailed information on building statistics are generally available at the National level and become less reliable when applied to individual states or regions. So we have used National data on building characteristics and then we apportion the results based on the relative use in California compared to the U.S.

\subsubsection{Total Floor Space By Building Size Category}

EIA CBECS provides this data for U.S. commercial buildings (U.S. EIA 2003), which is plotted in Figure 2. 


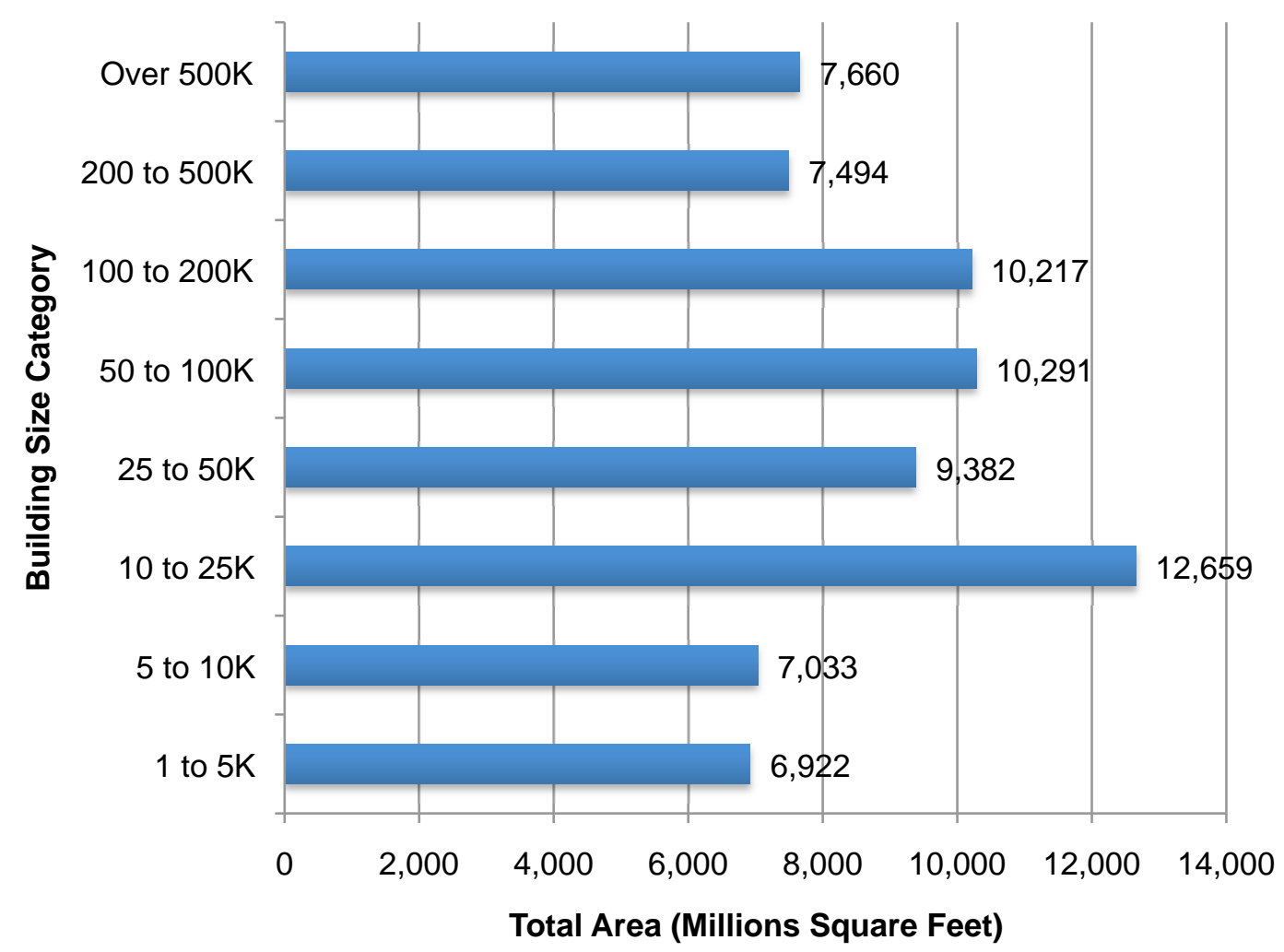

Figure 2. The total area of the U.S. commercial building inventory, classified according to building size.

Note that almost exactly half the total floorspace ( 35.7 billion out of 71 billion square feet) is in buildings that are greater than 50,000 square feet in size. Since the lighting power density (watts per square foot) in buildings is not strongly dependent on the buildings' size, we can assume that roughly half the total U.S. commercial lighting load also appears in large buildings.

\subsubsection{Number of U.S. Buildings By Building Size Category}

The total number of U.S. buildings broken down by size category is presented in Figure 3. 


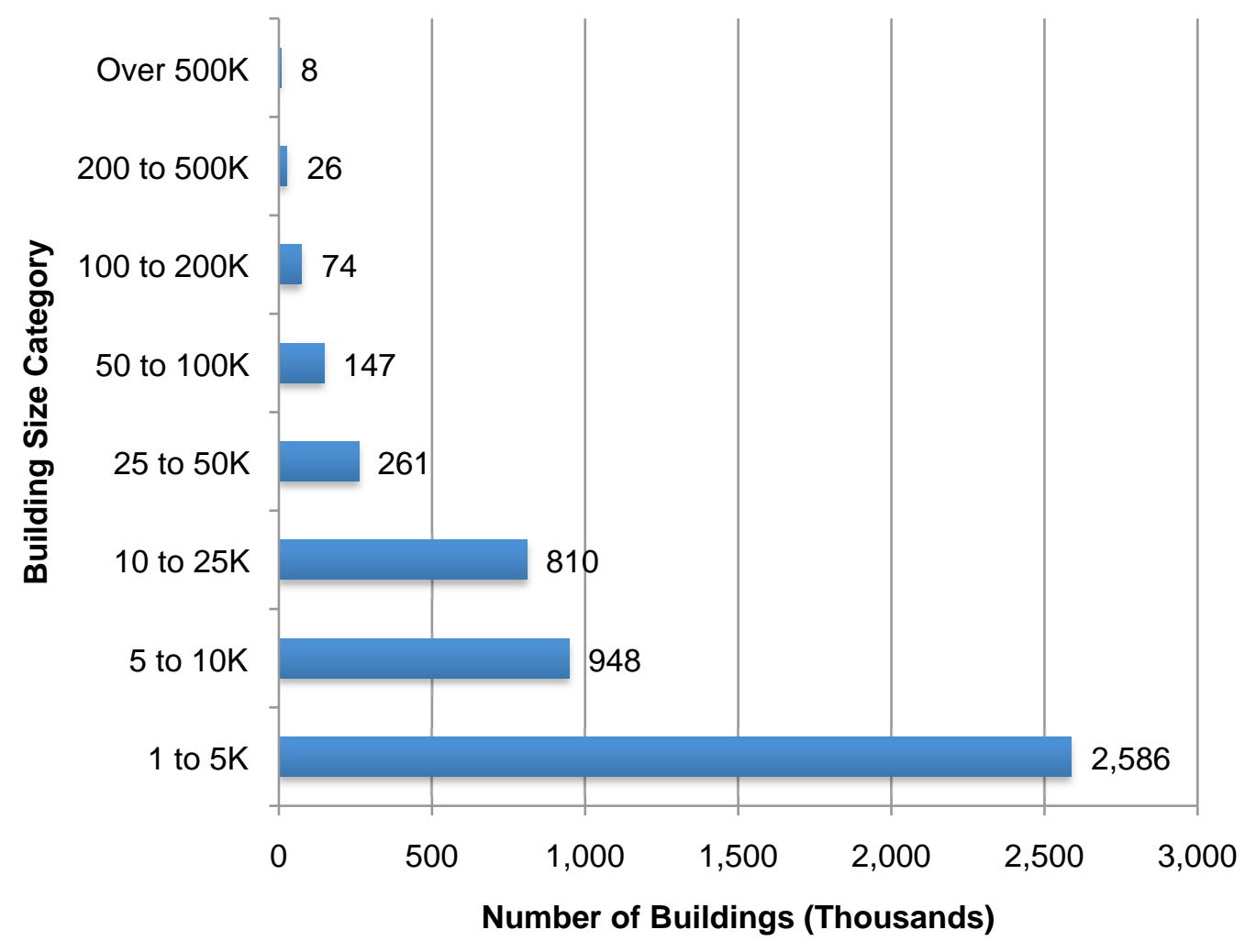

Figure 3. The total number of U.S. commercial buildings, classified according to building size category.

A significant finding of the building characteristics data is that only about $255,000(5 \%)$ of the over 4,859,000 million buildings in the Nation are 50,000 square feet or larger. Stated in terms of the estimated California commercial building market, this means that roughly $50 \%$ of the Statewide commercial lighting load (about 3 Gigawatts of an estimated 6 GW commercial building lighting load) is concentrated in just 25,000 buildings. This is advantageous from a DR implementation viewpoint, since it reduces the number of customer accounts required to implement this advanced form of ancillary services. Furthermore, larger buildings are more likely to have Lighting Energy Management Systems that can be leveraged to greatly reduce the cost of implementing dimming technologies. Finally, larger buildings are more likely to have an identifiable facilities management department that is more likely to amenable to savings operating costs in such a complex fashion.

\subsubsection{Technical Potential for Regulation Capacity and Contingency Reserves}

Figure 4 shows the estimated Statewide technical potential for regulation capacity and contingency reserve capacity in large buildings ( $>50,000 \mathrm{sf})$ and small buildings ( $<50,000 \mathrm{sf})$. The technical potential refers to the energy (or power) saving potential of the technology assuming it is employed everywhere technically possible without regard to economics or market potential. There is roughly $450 \mathrm{MW}$ of regulation "up" and "down" reserves available from dimmable lighting in buildings larger than 50,000 sf. By comparison, the entire requirement for regulation up and regulation down reserves in 2007 was $400 \mathrm{MW}$. The technical 
potential for dimmable lighting in large buildings providing contingency reserves would be 2.5 GW assuming the extreme case where all lighting in large California commercial buildings were dropped from $100 \%$ to $25 \%$ power.

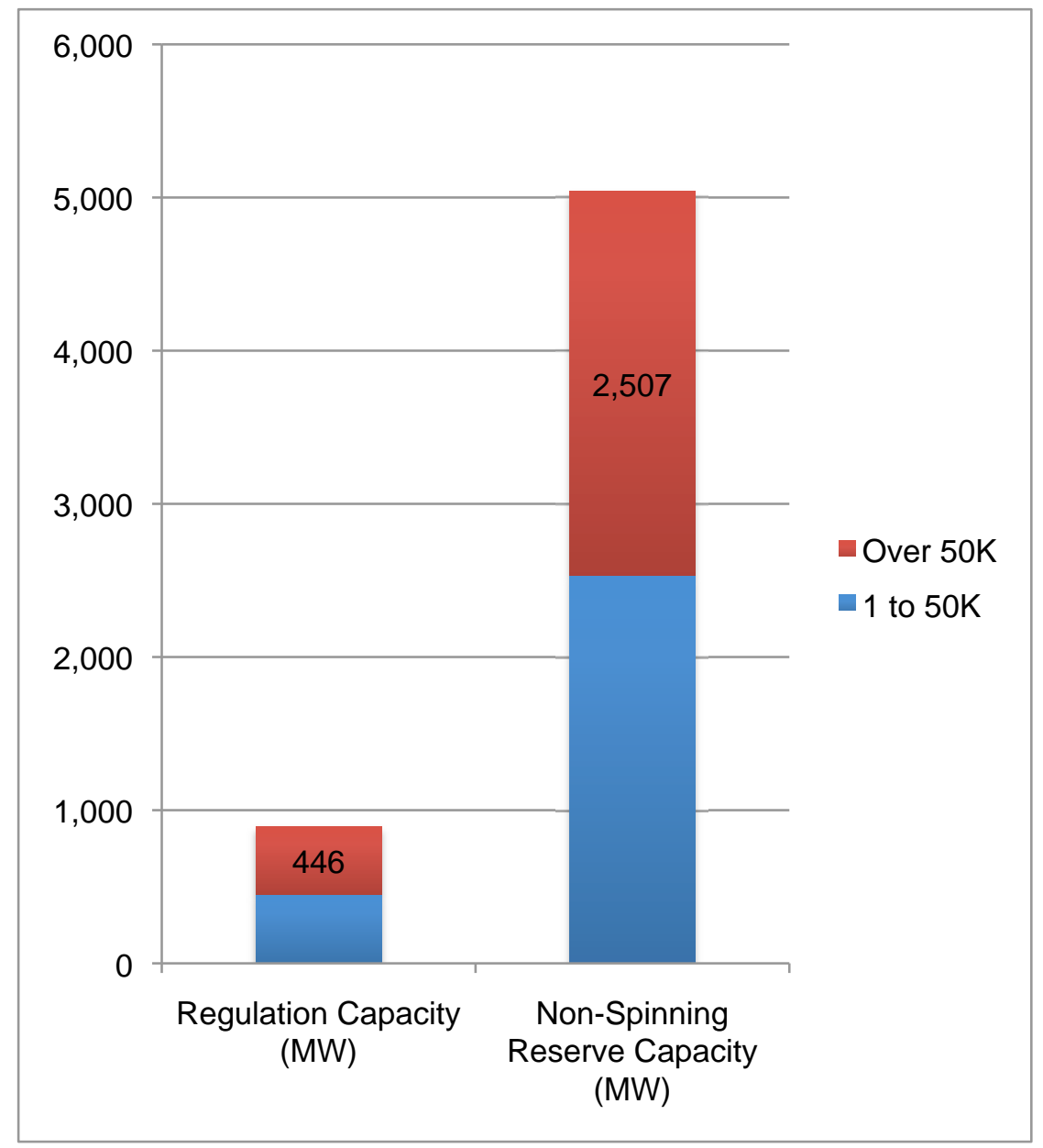

Figure 4. The estimated Statewide potential for regulation capacity and contingency reserve capacity broken down according to large $(>50,000$ sf) buildings and small buildings ( $<=50,000$ sf).

Figure 5 shows the technical potential for dimmable lighting providing regulation capacity and contingency reserves Statewide, broken down into building size categories. 


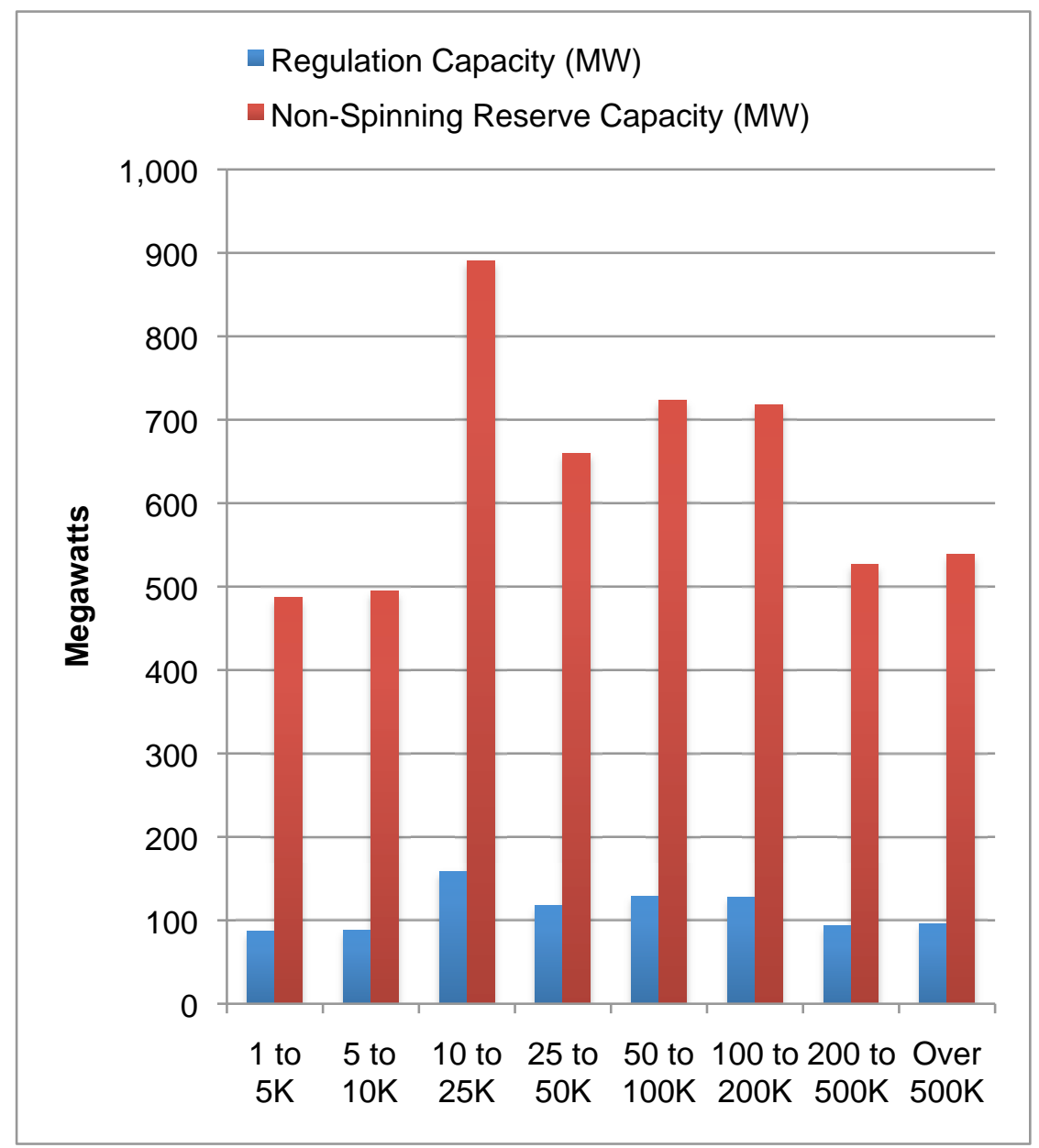

Figure 5. The estimated Statewide potential for regulation capacity and contingency reserve capacity broken down according to eight building size categories.

\subsubsection{Economic Potential for Regulation Capacity and Contingency Reserves}

In the above section, we have estimated the maximum technical potential for using dimmable lighting in all large commercial buildings for regulation and contingency reserves. A more practical measure, economic potential, takes into consideration economics and estimates of market potential and penetration rates, which generally conspire to lower the actual potential power savings available to dimmable lighting. Furthermore, if dimmable lighting is massively deployed throughout the State for purposes of improving energy efficiency, then a good fraction of the Statewide lighting load would already be partly dimmed at any given time leaving less power available for A/S.

The most important determinant is the assumed saturation level of the dimming controls. In an earlier scoping study (Rubinstein and Kiliccote 2007), we presented three saturation levels (15, 30 , and $60 \%$ saturation) that reasonably sample the range of possible saturation levels for dimmable lighting in the State. To obtain $60 \%$ saturation generally requires mandate by state building code or national standard. It took the electronic ballast nearly 20 years after introduction to reach this saturation level, but reach it, it did, in large part because of 
Cailfornia's aggressive Title 24 Building Code. Without the stick provided by building code or appliance standard, lower saturations would be achieved depending on whether the incremental cost is recovered quickly ( 30\% saturation) or slowly ( 15\% saturation).

Another factor to be considered is that even if the dimmable lighting and communications infrastructure were in place, it is not reasonable to assume that every site would participate fully. Indeed, unless it was mandated, actual participation of an equipped site would always be less than $100 \%$.

Here, it is useful to treat dimmable lighting for regulation reserves and contingency reserves separately because the potential impacts on occupant comfort and satisfaction may not be the same. The authors are of the belief that dimmable lighting implemented properly, could be used for regulation reserves sufficiently infrequently throughout the day that no individual site would suffer any degradation in user comfort. Thus properly implemented, dimmable lighting used for regulation reserves should be sufficiently inconspicuous that it could be used universally where the infrastructure is installed.

The user acceptance of dimmable lighting for contingency reserves may be another matter entirely, since the reductions in light level could be as large as $80 \%$; something that is likely to be quite conspicuous to the building occupants. On the other hand, contingency reserves would only be called for perhaps 100 hours a year and if the incentives to individual businesses are sufficiently enticing, enterprises may be willing to have their lighting noticeably dimmed since it would only affect business operations for limited time periods.

Several research institutions have examined the occupant acceptance of temporarily lowered light levels in simulated office environments. This research, while not comprehensive, seems to indicate that dimming electric light levels $15-25 \%$ from the maximum available are not likely to be noticed by most occupants. Reductions of $40 \%$ below maximum (60\% light output) are generally noticed and are accepted by some $50 \%$ of occupants. Reductions of $60 \%$ below maximum (40\% light output) will be accepted by roughly $50 \%$ of occupants if accompanied by an alert as to why the reduction is necessary. An example of this would be a Stage 2 alert called by the local IOU during times of grid stress. Newsham (2008) found that reductions as large as $80 \%$ from maximum (20\% light output) were acceptable only in well daylighted spaces.

In Figure 6, we present a reasonable user compliance model based on the assumption that the more contingency reserves requested from a site, the lower the actual compliance with the shed will be. Under this assumed model, there would $90 \%$ compliance with a requested contingency reserve reduction of no more than $30 \%$ of full power, but would only $20 \%$ compliance with a requested reduction of $60 \%$ or more of full power. 


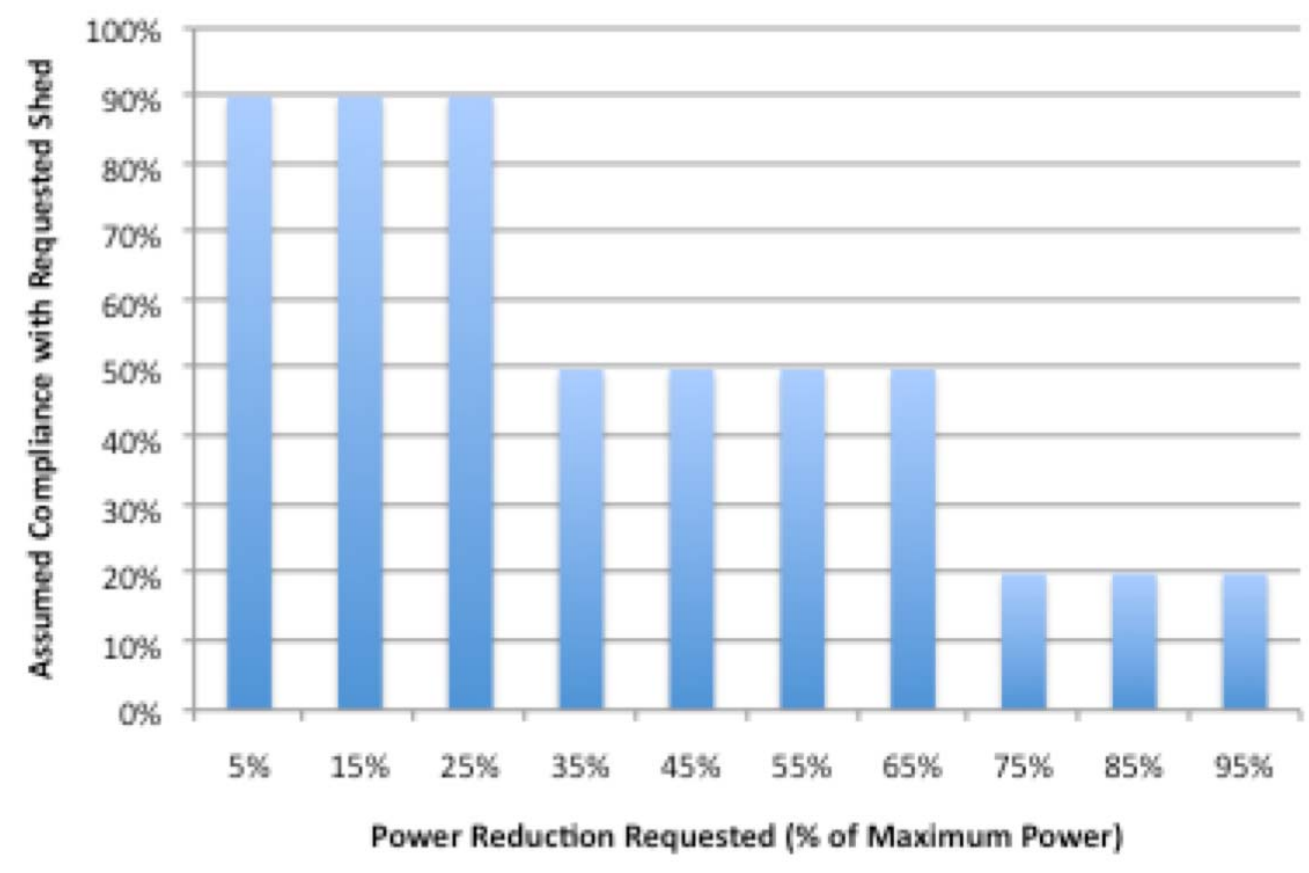

Figure 6. Assumed user compliance plotted against power reduction requested (as \% of maximum power).

Finally, we must consider that even a site that is willing to reduce load for contingency reserves, may already be operating the lighting at less than full power (because they are implementing the various energy efficiency strategies such as daylighting and personal controls). Under such circumstances, only some of the lighting could be shed. It is difficult to generalize, but the authors have assumed that, on average, the lighting system is only operating at $75 \%$ of full capacity. This serves to reduce the amount of capacity available for contingency reserves by $25 \%$.

By convolving these "informed estimates" of assumed compliance with the different penetration scenarios described previously, we have constructed Table 1 to estimate the economic potential of dimmable lighting for contingency reserves. The economic potential is expressed in terms of absolute MW and also relative to the contingency reserve requirement for 2007.

Table 1. Economic Potential of Contingency Reserve from Dimmable Lighting in Large Commercial Buildings for Three Market Penetration Scenarios

\begin{tabular}{|c|c|c|c|}
\hline & $\begin{array}{c}\text { Scenario 1: Use } \\
\text { Mandated by Code } \\
\mathbf{6 0 \%} \text { saturation }\end{array}$ & $\begin{array}{c}\text { Scenario 2: Deep } \\
\text { penetration of } \\
\text { dimming } \\
\mathbf{3 0 \% \text { saturation }}\end{array}$ & $\begin{array}{c}\text { Scenario 3: } \\
\text { Business-As-Usual } \\
\mathbf{1 5 \%} \text { saturation }\end{array}$ \\
\hline Megawatts & $380 \mathrm{MW}$ & $190 \mathrm{MW}$ & $95 \mathrm{MW}$ \\
\hline $\begin{array}{c}\text { \% of All Non-Spinning } \\
\text { Reserve (2007) }\end{array}$ & $47 \%$ & $24 \%$ & $12 \%$ \\
\hline
\end{tabular}


To summarize, if dimmable lighting is massively deployed throughout large California buildings because mandated by law, dimmable lighting could realistically supply $308 \mathrm{MW}$ of contingency reserve - a significant $47 \%$ of the total contingency reserves needed in 2007 . Under a business-as-usual scenario, dimming lighting would only penetrate $15 \%$ of large commercial buildings, reducing the estimated economic potential to about $130 \mathrm{MW}$ (12\% of 2007 needed contingency reserves).

\subsection{Number of Potential New Ancillary Services Accounts}

At the present time, only large generators can bid into the ancillary services market. There are only about 100 of these large generators that provide these services for the entire grid under the auspices of the CAISO. From an administrative point of view, it is may seem preferable to have only a relatively few large generators provide all ancillary services. After all, the fewer the number of large accounts that are able to provide A/S services the lower the overall cost, all other things being equal.

If dimmable lighting is to be used to provide some proportion of the A/S currently provided by large generators, then it stands to reason that there could be a much larger number of customer accounts that would have to be serviced by the ISO.

Using data from Kiliccote et al (2009), we have calculated the approximate number of customer accounts as a function of building size and number of establishments per building for large California buildings. (As before, we are not including buildings smaller than 50,000 $\mathrm{ft}^{2}$.)

From Table 2, it is seen that the number of customer accounts that the ISO will have to administer would increase by roughly one thousand; that is from about 100 accounts to 107,000 accounts.

\section{Table 2. Number of California Commercial Buildings in Different Size Categories and Estimate Number of Accounts}

\begin{tabular}{|c|c|c|c|c|}
\hline $\begin{array}{c}\text { Building Size } \\
\text { Category (square } \\
\text { feet) }\end{array}$ & $\begin{array}{c}\text { Estimated Number } \\
\text { of Buildings in CA }\end{array}$ & $\begin{array}{c}\text { Number of } \\
\text { Establishments } \\
\text { Per Building }\end{array}$ & $\begin{array}{c}\text { Area Per } \\
\text { Establishment }\end{array}$ & $\begin{array}{c}\text { Estimated } \\
\text { Number of } \\
\text { Accounts }\end{array}$ \\
\hline 50 to 100K & 14,700 & 3.8 & 19,735 & 55,400 \\
\hline 100 to $200 \mathrm{~K}$ & 7,400 & 4.2 & 39,475 & 31,400 \\
\hline 200 to 500K & 2,600 & 4.7 & 92,105 & 12,300 \\
\hline Over 500K & 800 & 10.2 & 223,370 & 8,150 \\
\hline $\mathbf{5 0 K}$ & $\mathbf{2 5 , 5 0 0}$ & 5.7 & & $\mathbf{1 0 7 , 2 5 0}$ \\
\hline
\end{tabular}




\subsection{Dimmable Lighting Characteristics}

Previous research has described the importance of using dimming ballasts for obtaining the best performance with respect to unobtrusively varying light output (and therefore power drawn) so that occupants will not be annoyed when demand-responsive lighting is being carried out on a regular basis.

This section considers the technical performance of modern dimming fluorescent ballasts to identify the amount of power that could be realistically squeezed out of controllable lighting systems if they were to be applied universally.

Figure 7 shows the input power/light output curve for a typical modern dimming ballast (2x32 watt T-8 fluorescent lamps).

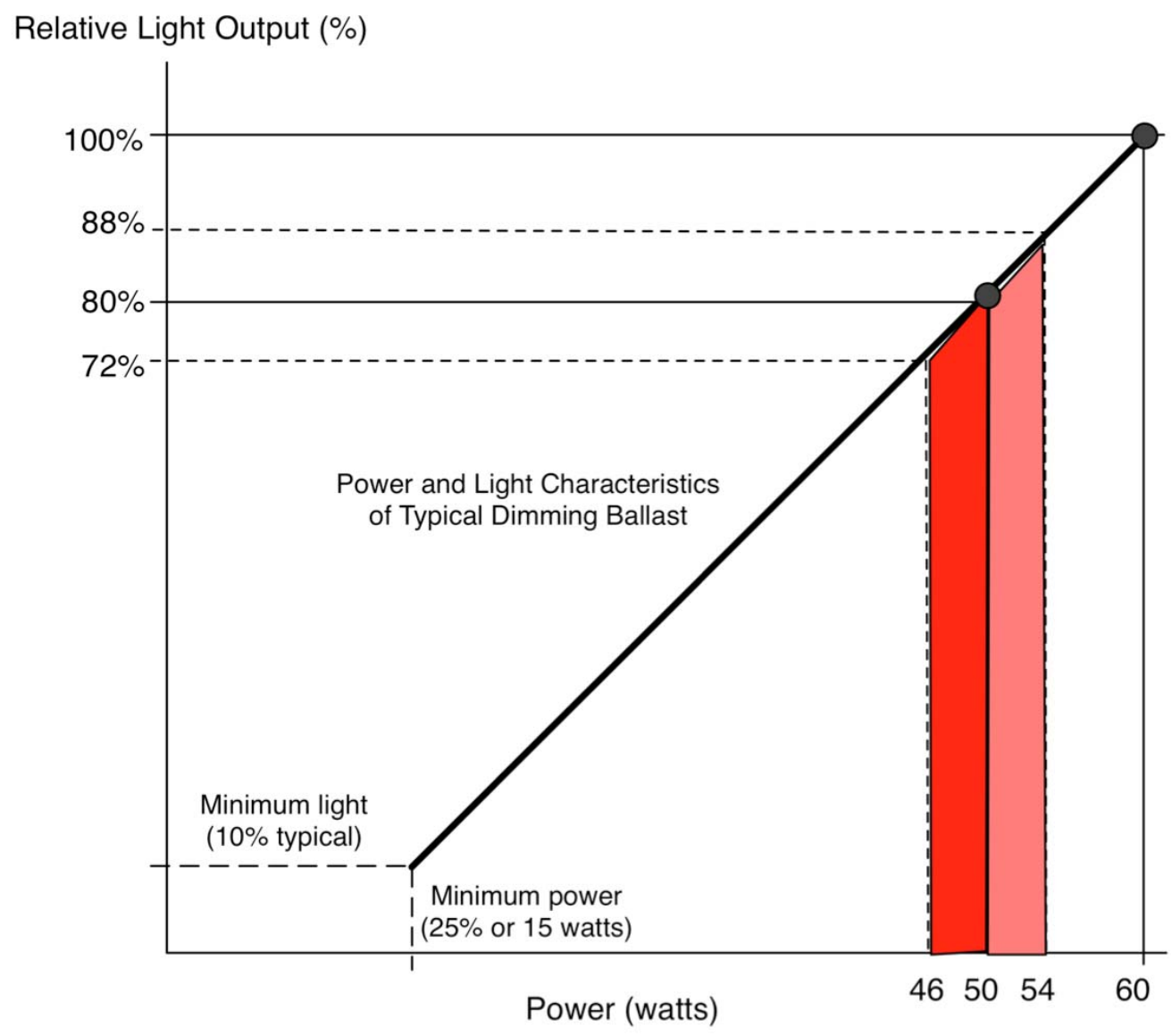

\section{Figure 7. Typical input power, light output curve for a modern fluorescent dimming ballast.}

As shown in Figure 7, the power input to a two-lamp dimming ballast can vary from a low of 15 watts to nominal full power (about 60 watts). Assuming that the ballast is operating at a nominal $80 \%$ light level, the power drawn per ballast is 50 watts. If the ballast output were dropped by $8 \%$ relative to this nominal operating point, as would be the case in regulation up, 
the ballast would draw 4 watts less (about 46 watts). If, on the other hand, the ballast output were to increase by $8 \%$ relative to the nominal point, as would be the case in regulation down, the ballast would draw 4 watts more. The plus and minus $8 \%$ excursions from the nominal operating point were selected to correspond to those used in NRC's test protocol (Newsham et al 2008).

In the case of using dimmable lighting for contingency reserves, however, the entire dimming range is available. Thus, even if a ballast were operating at a nominal $80 \%$ light level, there should always be at least 35 watts of sheddable load (and possibly as much as 45 watts) available per dimming ballast, without ever having to extinguish a light.

\subsubsection{Latency of Dimming}

Both analog and digitally controlled fluorescent ballasts can alter their light output (and power draw) in a matter of seconds. Furthermore, unlike chillers and other types of A/C equipment, dimmable lighting ballasts can be set to any intensity within their control range. In this regard, dimmable lighting is ideal from an interruptable load perspective since the energy service provided by the ballast can be altered just slightly making its effects almost unnoticeable to the building occupants. In addition to the few seconds it takes to command a ballast to change its light output, it will also take a few seconds for the command to percolate down the network from the point of origin (presumably the ISO) to the final dimming points. However, even making conservative assumptions about network latency, it seems unlikely that dimmable lighting would take any longer than about 1 minute to reach the final desired state once the dimming command has been issued. This should make dimmable lighting technically competitive with large generators, which have response times of over a minute. On the other hand, as is discussed in the next section, it would require hundreds of thousands or millions of dimmable ballasts to be deliberately controlled in order to provide a large aggregate effect that would be of use to the ISO.

\subsection{Total Statewide Potential for Dimmable Lighting}

Using the information in the previous sections, we can estimate the Statewide potential for using dimmable lighting for both regulation and contingency reserves based on the following typical assumptions or approximations:

1. The total California commercial building area is $10 \%$ of the National data from CBECS.

2. The total number of buildings and building size distribution are also $10 \%$ of National number.

3. There is one two-lamp fluorescent dimming ballast per luminaire.

4. There is one luminaire installed every 64 square feet of CA commercial building space.

5. When used for regulation capacity control, each dimming ballast can either:

a. Provide regulation "up" control by decreasing its power draw by 4 watts from a nominal $80 \%$ of full power or

b. Provide regulation "down" control by increasing its power draw by 4 watts from a nominal $80 \%$ of full power. 
6. Alternatively, each dimming ballast can provide up to 45 watts / ballast of contingency reserve capacity by dimming to minimum ( $25 \%$ of full power) in response to a severe DR event.

\subsection{Types of Lighting Controls}

New lighting control networking technologies now allow controlled lighting systems to dim the lighting in response to grid stress, real time pricing or to supply ancillary services. There are two categories of dimmable ballast that are germane to this discussion: analog control and digital control. As was discussed in Rubinstein and Kiliccote (2007) most analog control ballasts use the 0-10 VDC control "protocol" while most digital ballasts use the DALI protocol.

Historically, analog controlled dimming ballasts are usually controlled in groups or zones in which all the ballasts in a given zone dim to the same level in unison. Analog zone control is useful in commercial buildings, especially in conference rooms or in daylighted big box stores. However, analog zone controls are inflexible with respect to future re-zoning of the lighting system, which occurs, on average, once every 15 years. Also, there are inconsistencies in the operation of 0-10 VDC analog ballasts, even within the same manufacturer. At the present time, there are more analog dimming ballasts to accommodate a wider variety of lamp types than DALI.

Several manufacturers have developed lighting control networks that use 0-10 VDC dimming ballasts, but use a purpose-built A/D module on each ballast (or each fixture) that dims the ballast but allows the dimming operation to be controlled from a RS-485 digital network. This allows individual dimming ballast control that is essentially identical to a digital dimming ballast.

\subsubsection{Analog point-to-point control}

An example of a lighting control network that provides individual control of analog ballasts is shown in Figure 8:

Maximum of 256 Addressible Analog Dimming Ballasts

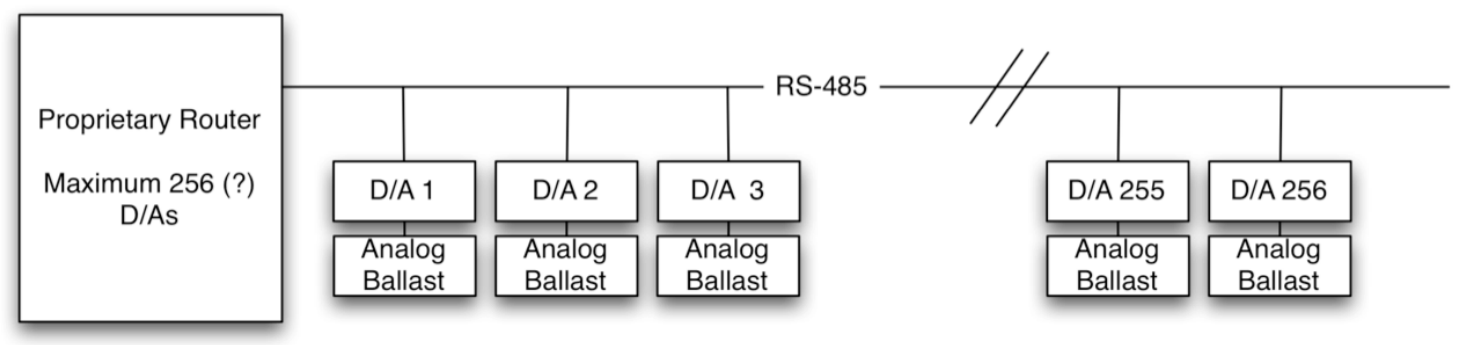

Figure 8. Generic network diagram for controlling individual analog dimming ballasts from a digital network.

This configuration has some advantages over a DALI digital system. First, for the moment anyway, analog dimming ballasts cost \$5-10 less per ballast than DALI ballasts. The RS-485 
digital network that most manufacturers use to connect the different D/A modules is based on a mature technology and is very reliable once configured correctly.

\subsubsection{DALI lighting control system}

An alternative method to control individual ballasts is to use a digital control protocol, such as DALI (see Figure 9). Although there are other digital protocols in use in the U.S. today, DALI is the dominant digital protocol used by most dimming ballast manufacturers. DALI ballasts have several advantages. First, there is a fair degree of consistency amongst the different DALI ballast manufacturers. This means that a DALI input value of, say 185, commands the connected DALI ballast to about the same dim level regardless of manufacturer. This makes it easy to select the hardware and software somewhat independent of ballast manufacturer. However, DALI is also a limited ballast control protocol. All successful DALI manufacturers have had to develop lighting control software that adds a great deal of functionality that raw DALI lacks.

\section{Maximum of 32 Workstation-Specific Luminaires Per Channel} ( 2 DALI ballasts per luminaire)

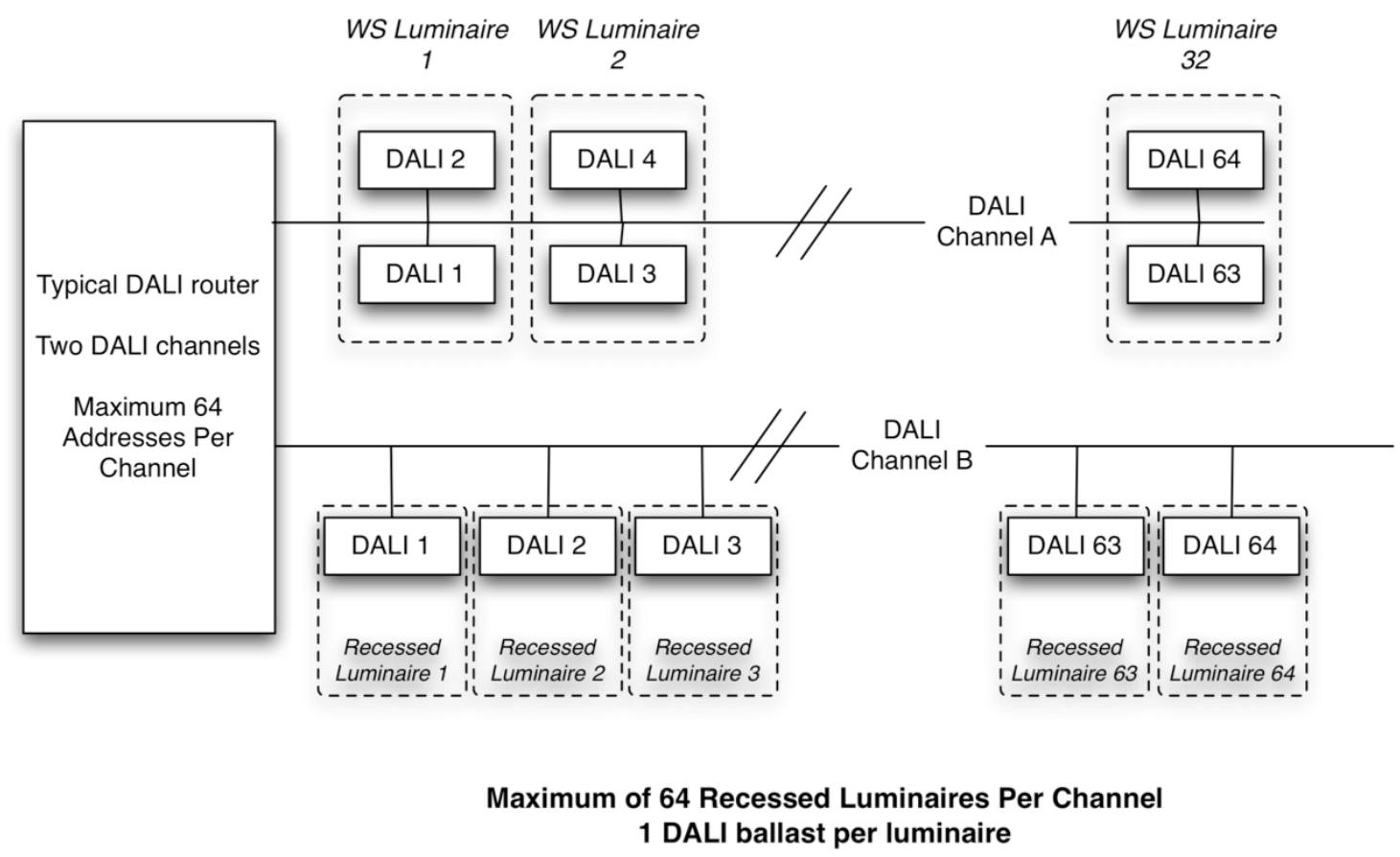

Figure 9. Generic network diagram for a DALI lighting control system

Both analog and digital system architectures are available from multiple lighting control manufacturers.

From this, we conclude that there exist appropriate dimming ballasts as well as the associated control equipment that would allow California to implement a wide scale lighting control infrastructure to provide ancillary services meeting the spirit of the ISO requirements. 


\subsection{CAISO Technical Requirements}

This section of the report focuses on the CAISO's technical requirements for regulation capacity and contingency reserves and describes some of the challenges in using dimmable lighting to meet the CAISO's strict requirements. All ancillary services are currently required to have a minimum rated capacity of $1 \mathrm{MW}$ or greater.

\subsection{Current Regulation Up and Regulation Down Requirements}

At the present time, the CAISO has the following technical requirements for generators that wish to provide Regulation as an Ancillary Service (CAISO 1999):

1. The maximum amount of Regulation to be offered must be reached within a period from 10 minutes (minimum) to 30 minutes (maximum).

2. A direct digital control signal produced by the ISO Energy Management System through a standard ISO direct communication

3. Power output response to a control signal must respond immediately without manual operator intervention throughout the event.

4. Direct communication and control system to send signals to EMS to dynamically monitor key technical parameters, such as actual power output

5. Additional requirements with regards to telephone connectivity with the ISO

\subsection{Current Spinning Reserve Requirements}

The CAISO currently has the following technical requirements with regards to generators providing spinning reserves from a Generating Unit or System Resource:

1. Minimum governor performance of $5 \%$ drop with a deadband of $0.036 \mathrm{~Hz}$. The power output must change within one second of any frequency deviation.

2. Operator must be able to receive Dispatch instruction to initiate an increase in real output power within one minute.

3. Must be able to increase real power output by the maximum amount of spinning reserve to be offered within one minute.

4. Primary and backup voice communication link between ISO Control Center and the operator.

\subsection{Current Non-Spinning Reserve Requirements}

The CAISO currently has the following technical requirements with regards to Ancillary Service Provider providing AS from a Generating Unit, System Resource or Interruptible Load:

1. Must be able to increase output as soon a possible to the promised value, reaching the indicated value within 10 minutes and able to sustain that output for 2 hours.

2. Operator must be able to receive Dispatch instruction to initiate an increase in real output power within one minute. 


\subsection{Proposed Changes to ISO Requirements}

In a recent concept paper (Tretheway 2009), the ISO proposed a Strawman Proposal that would modify some of the technical requirements for A/S providers. Most germane to this Feasibility Study are the loosened requirements with respect to the definition of an Ancillary Services Provider as well as the minimum run time requirements. In the strawman proposal, ancillary services would not be technology specific. In other words, interruptable, controllable loads could compete with power generators on a level playing field. In addition:

1. The minimum run time requirements for non-spinning and spinning reserves will be reduced from 2 to 1 hour.

2. The minimum run time requirement for regulation up and regulation down will be 1 Hour for the Day Ahead market and 15 minutes for the Real Time Market.

It is expected that these new requirements will make it easier for distributed dimmable lighting to provide non-spinning reserves than under the current requirements, because the reduced light level would only be required for one hour rather than two. 


\subsection{Assess Occupant Acceptance}

Notwithstanding all the technical analysis that is performed in this feasibility study, the use of dimmable lighting for regulation capacity or non-spinning reserves will not be accepted if it significantly affects the ability of people to see and accomplish productive visual tasks in the working environment.

Two key issues to be addressed in this task are:

1. How frequently would alternative regulation up and down events occur per day (on average)?

2. What are the effects of oscillatory lighting on human comfort and satisfaction? Are there negative performance implications?

\subsection{Frequency of Regulation Up and Regulation Down}

Based on the experience with conventional generators used for providing ancillary services, it is likely that an A/S provider may need to switch from regulation up to regulation down many times within a single day in order to provide for the real-time market needs for regulation capacity control. In this regard, dimmable lighting is an almost ideal load to control for this purpose since the power drawn by a single dimming ballast can be continuously varied. The rate of change and magnitude of change of dimming ballasts may be limited primarily by the perception (or lack thereof) by building occupants. To be most valuable as an ongoing resource, dimmable lighting could be varied minimally on a regular basis for reg up and reg down events. It could be varied substantially for infrequent contingency based events. Lighting variations are not limited by mechanical, electrical and thermal constraints found in traditional use of heating ventilating and air conditioning (HVAC) for demand response.

\subsection{Comfort and Satisfaction Considerations}

Most of the research in this area has been performed by the National Research Center of Canada (NRC) under the direction of Guy Newsham (Kiliccote et al 2009). Their work has shown three key findings:

That people are relatively insensitive to two cycles of slightly varying electric light level (17\% change) where both cycles were 20 seconds long.

That people in well-daylighted spaces are tolerant of quite large reductions in electric lighting (up to $80 \%$ ).

That people generally accept deeper reductions in electric lighting power if they are notified ahead of time.

The first finding was discussed in a paper in which the subjects were subjected to a different fluctuating lighting waveforms as described below. In the "unidirectional" presentation (see Figure 10), the maximum light level was followed, after 10 seconds by a "baseline" level for 20 seconds after which was a 10 second ramp to one of 5 final dimmed levels $(20 \%-80 \%)$. Subjects were asked their response 45 seconds after the final dimmed level was reached. In the "sawtooth" presentation (see Figure 10), an initial maximum light level was followed, after 10 seconds, by a "baseline" level for 20 seconds after which light levels fluctuated over $20 \%$ range 
in a sawtooth pattern for two whole cycles. Again, subjects were asked their response 45 seconds after the initiation of the sawtooth pattern.
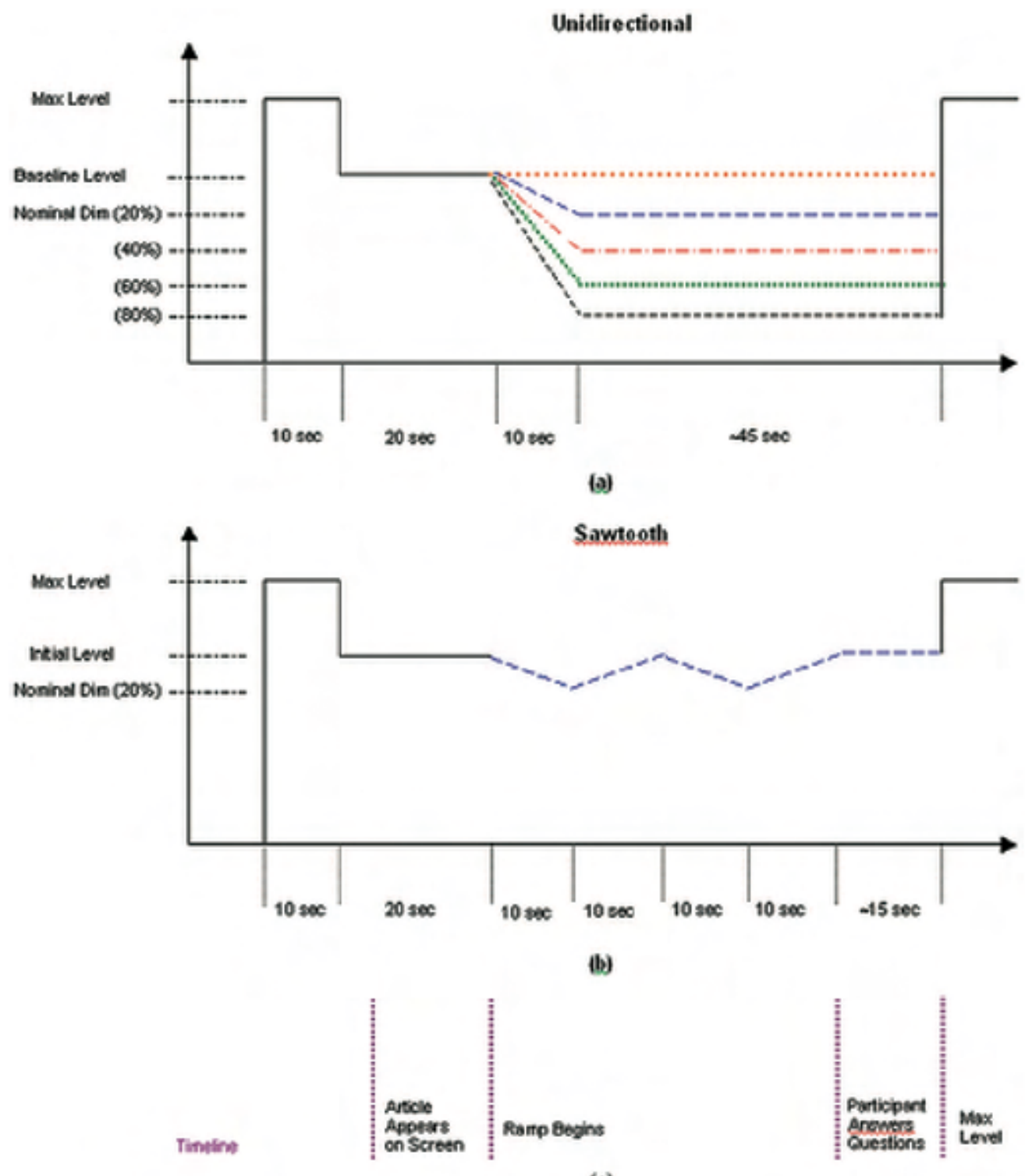

(c)

Figure 10. Different light level fluctuations presented to test subjects to assess occupant acceptability of varying light levels.

The reactions of test subjects presented with the "unidirectional" stimulus were compared to the reactions obtained when the light level varied with the "sawtooth" pattern. The sawtooth lighting pattern was found to be acceptable to $86-92 \%$ of occupants - the same level of acceptability as the unidirectional presentation. Newsham's work suggests that occasional, short-term, small fluctuations in electric light level (18\% of full light output) may not be bothersome to occupants. 
However, the authors do not suggest that this is proof that small excursions in light level would be acceptable if they occurred constantly or even frequently throughout the working day. But it does suggest that light levels can be occasionally slightly shifted without causing notice as long as the shifts are infrequent (say 4 times a day). One of the challenges facing this type of fast DR will be developing the controls and communications infrastructure and fast DR resource aggregators that would be capable of implementing regulation reserves over a region without excessively oscillation of light level at any implementing site.

Newsham also examined the effects of a single level light reduction in non-daylighted spaces as well as spaces with both high and low amounts of available daylight. These results are germane to anticipating any potential negative occupant response to significant amounts of dimming as might occur during a Stage 2 Power Emergency.

In one set of experiments, electric light levels were varied by $20 \%$ to $80 \%$ in varyingly daylighted rooms and the percentage of subjects noting and accepting the provided light levels measured. In Figure 8, it is seen that 50\% of people don't notice a 35\% reduction in light level regardless of daylight level. Figure 11 shows that more than $75 \%$ of people will accept a light level reduction of $40 \%$ regardless of daylight level. In a well-daylighted space, $90 \%$ of people will accept an $80 \%$ light level reduction while $60 \%$ will accept such a light level reduction in a low-daylighted space.

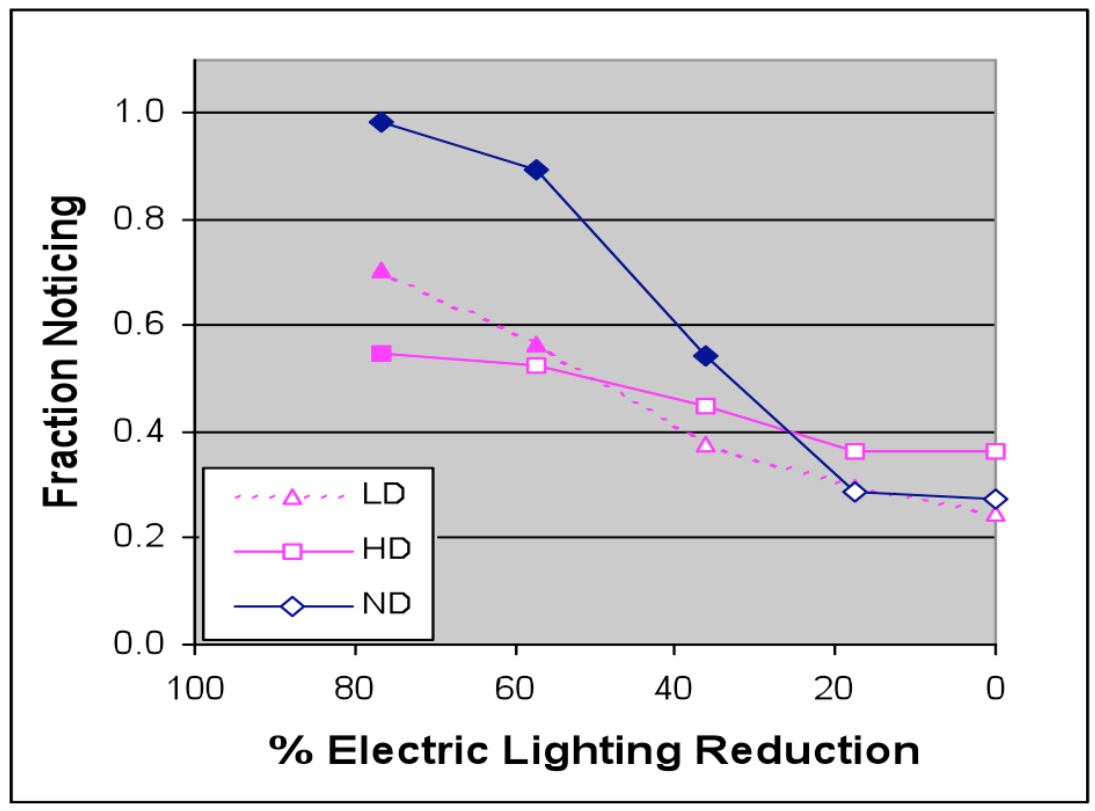

Figure 11. Fraction of subjects noticing different electric lighting reductions in daylighted and non-daylighted spaces. 


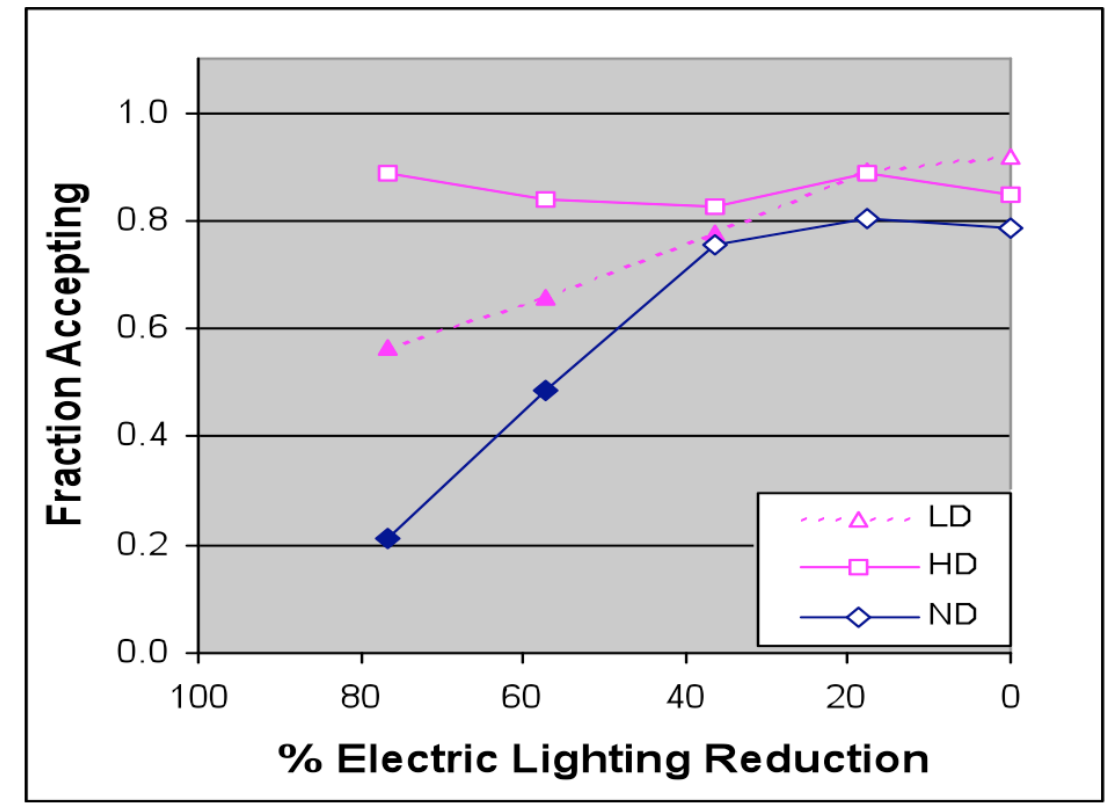

Figure 12. Fraction of people accepting different electric light level reduction in daylighted and non-daylight spaces.

This research suggests that people in daylighted spaces are tolerant to relative large changes in provided electric light level as long as the lighting is dimmed rather than switched. 


\subsection{Communications}

In order to effectively use dimmable lighting to provide regulation capacity and contingency reserves, it would be necessary to control millions of tiny loads in unison very quickly. As previously described, time scales to initiate and achieve substantial demand reductions are in the 4 to 10 second range. In order to meet these stringent requirements, careful planning of the communications infrastructure is necessary. With proper planning and design, research indicates that use of existing state-of-the-art networking and telecommunications equipment would be adequate for the applications described in this paper. As part of the design process, the dimmable lighting assets must be divided into physical and logical groups. The architecture and grouping must be designed with the following considerations:

1. Geographic regions that are useful to the CAISO or other entities

2. Communications topology that will minimize signal communications latencies

3. Minimize costs

a. Network hardware, routers, gateways, wireless base stations etc.

b. On site lighting control equipment

c. Recurring costs due to dedicated communication links, network operations, maintenance etc.

4. On-site lighting and control systems that are applicable to various types of building structures, property ownership, occupancy and management structures.

The Public Internet, private IP networks, utility system control and data acquisition (SCADA) and wireless communication systems have been used extensively in automated demand response research, pilots and programs. Though much of the work has been implemented in day-ahead programs such as Critical Peak Pricing (CPP), recent tests in the wholesale markets Participating Load Pilot (PLP) have consistently reduced loads in less than one minute (Kiliccote et al 2009). In the Demand Response Spinning Reserve Demonstration (Eto et al 2007) researchers concluded: "The project team measured full load response in less than 20 seconds and identified technical opportunities to further increase response speed". Lab and statewide field research has shown that the public Internet can be used to consistently send demand response control signals (with receipt acknowledgement) throughout the state. Figure 13 shows a sample of 100 measurements, with an average roundtrip packet latency of 41.4 milliseconds (Watson and Motegi 2005). Private internet protocol (IP) based Enterprise networks can match or better these time scales. 


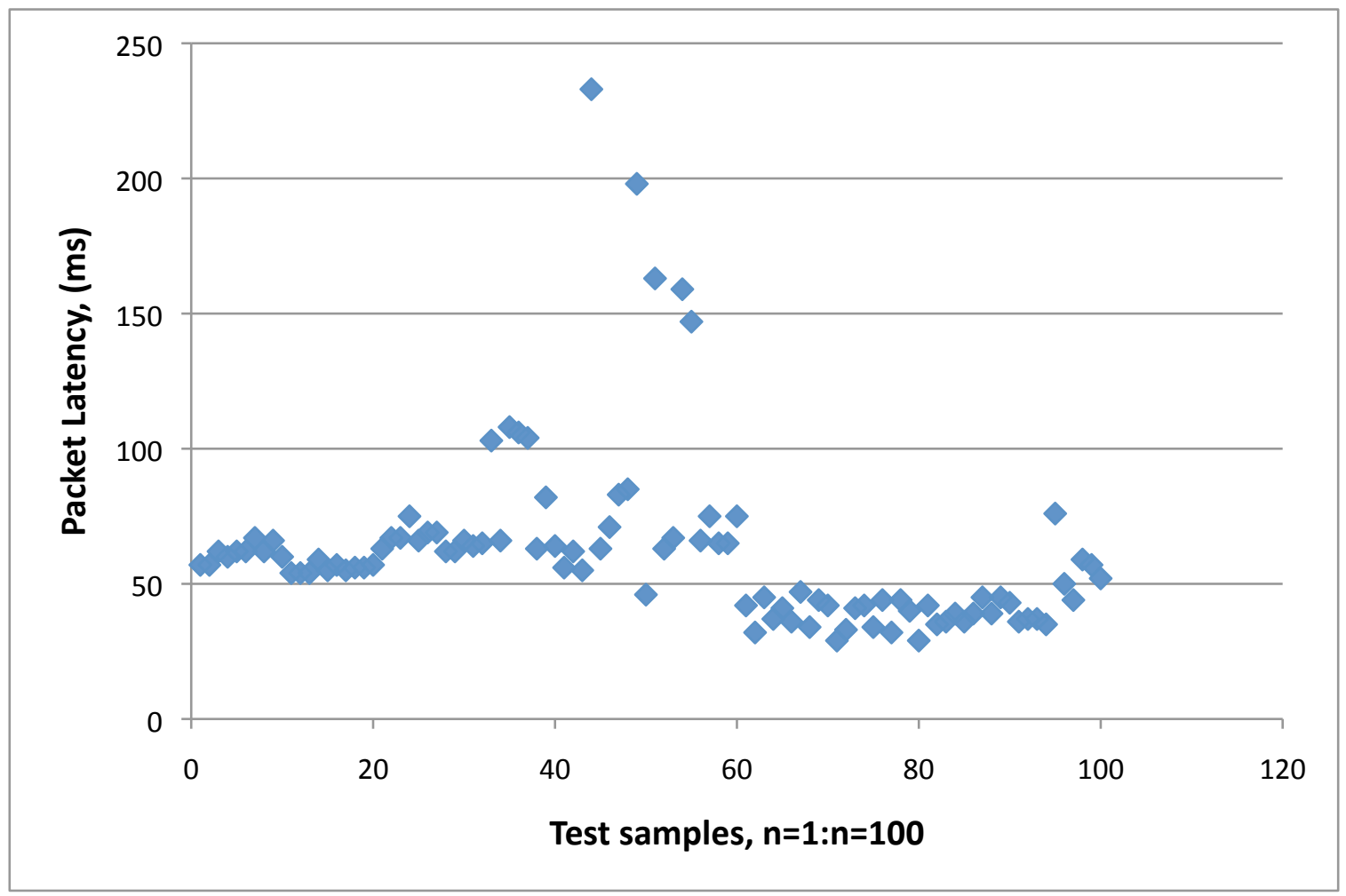

Figure 13. Demand Response control packet latency between software client and demand response automation server (DRAS) across the public Internet in Northern CA.

The pilots and demonstrations by Eto and Kiliccote measured end-to-end connectivity including the measured drop in controlled load. The Watson tests only include roundtrip transport of the DR messages across the Internet.

In addition to Internet and utility SCADA systems, wireless communications may be useful for widespread broadcast signals such as those that may be required in systems described in this report. 


\subsection{Findings}

These are the findings of the Feasibility Study:

1. Roughly one half of the total electric lighting load in the California commercial sector is bottled up in larger buildings that are greater an 50,000 square feet. There are roughly 25,000 large commercial buildings in the State that are in this size category, constituting about 3.6 billion square feet of floor space in California.

2. Retrofitting large California buildings with dimmable lighting to enable fast DR lighting (and other control strategies) would require an investment of about $\$ 1.8$ billion and would require a "fleet" of about 56 million dimming ballasts.

3. By upgrading the existing installed base of lighting and controls (primarily in large commercial facilities) a substantial amount of ancillary services could be provided. Though not widely deployed, today's state-of-the art lighting systems, control systems and communication networks could be used for this application. There are no technically insurmountable barriers to providing such an infrastructure.

4. The same lighting control equipment that is appropriate for fast DR is also appropriate for achieving energy efficiency with lighting on a daily basis. Thus fast DR can leverage the capabilities that are provided by a conventional dimming lighting control system.

5. Assuming that each dimming ballast can be ramped up or down by 4 watts from a nominal $80 \%$ operating level, there is about $450 \mathrm{MW}$ of regulation up or regulation down capacity available throughout large California buildings. This is more than the entire ISO requirement for regulation reserves for the year of 2007.

6. Assuming that each dimming ballast can be ramped down from full power to $25 \%$ power, the technical potential is $2.5 \mathrm{GW}$ of contingency reserve capacity available throughout large California buildings. The economic potential of dimmable lighting for contingency reserves is less due to market forces and economics.

7. If dimmable lighting were massively deployed throughout large California buildings (because mandated by law, for example) dimmable lighting could realistically supply $380 \mathrm{MW}$ of contingency reserve, $47 \%$ of the total contingency reserves needed in 2007. 


\subsection{Conclusions, Recommendations, \& Benefits to California}

\subsection{Conclusions}

This feasibility study concludes that using millions of dimming ballasts to provide regulation capacity control and contingency reserves (i.e. fast DR) is practicable assuming that the effort is focused on larger buildings - that is buildings over 50,000 square feet. These larger buildings are both more likely to install the dimmable ballast networks that would be required to make widescale dimming across facilities practical as well as have the built-in knowledge infrastructure to implement such advanced control schemes. Most importantly, the basic technical capabilities of advanced lighting control systems that are required to implement key energy efficiency strategies such as daylighting, occupancy control and personal controls are the same as are required to implement regulation capacity control and contingency reserves. Thus, once the dimming ballast networks and associated communications infrastructure are in place in California commercial buildings, there is little or no additional cost to implementing fast DR since the dimming equipment can be leveraged with only changes in software required.

We have shown that dimmable lighting deployed throughout large California buildings could provide nearly all of the regulation reserves required in 2007. We have also shown that dimmable lighting can provide significant contingency reserves to the grid during times of grid stress. However, economics and market forces will mean that other loads besides lighting would need to be shed to meet the State's entire contingency reserve requirements.

\subsection{Recommendations}

Implementing dimmable lighting for regulation capacity and contingency reserves will require a dedicated research, development, demonstration and deployment effort supported by the State and the ISO. The technical, institutional and economic issues are all complex, interlinked and multi-faceted.

As a part of future work, it would be of interest to examine dispatch logs to get a better handle on how much and how often regulation is used. Obtaining either a live feed or historical record from the ISO's AGC system, would provide useful data as input to researching the human factors implications as well as technology and implementation considerations.

Targeted human factors research should be conducted that identifies the limitations and possible detriments to human performance under realistic operating conditions. This work can be conducted in purpose-built testbeds that need not be expensive if creatively designed.

Finally, it is recommended that small pilot sites be identified where the implications of using dimmable lighting for regulation capacity can be explored in realistic, yet manageable applications. To keep costs to a minimum, these pilot studies should be performed in building spaces already equipped with dimmable lighting and already controlled by a modern, welldesigned and well-managed lighting control system that is Internet-accessible.

\subsection{Benefits to California}


If dimmable lighting were installed throughout large California buildings, it would provide the following benefits to California:

- A new, widely distributed demand resource that could meet most of California's needs for regulation capacity control in a typical year.

- A new source of demand resources that could supply a significant proportion of contingency reserves for California in a typical year.

- Increased use of fast DR should increase the supply of A/S offered into competitive markets leading to lower prices and increased competitiveness of these markets. 


\subsection{References}

California ISO Department of Marketing Monitoring, Market Issues and Performance (2007). 2007 Annual Report.

California ISO (2007), “Monitoring and Communications Requirements for Non-AGC Units Providing Ancillary Services, Technical Standards", Revision 5.7.

Eto ,J.H., J. Nelson-Hofmann, C. Torres, S. Hirth, B. Yinger, J. Kueck, B. Kirby, C. Bernier, R. Wright, A. Barat, D.S. Watson (2007). “Demand Response Spinning Reserve Demonstration." LBNL-62761

ISO Monitoring and Communications Requirements for Non-AGC Units Providing Ancillary Services, http: / / www.caiso.com/ docs / 1999/09/30/1999093015332016478.pdf

Kiliccote, S., M.A. Piette, G. Ghatikar, E. Koch, D. Hennage, J. Hernandez, A. Chiu, O. Sezgen, J. Goodin (2009). “Open Automated Demand Response Communications in Demand Response for Wholesale Ancillary Services". LBNL-2945E

Makarov, Y.V., J. Ma, S. Lu, T.B. Nguyen (2008). “Assessing the Value of Regulation Resources Based on Their Time Response Characteristics", PNNL-17632.

Newsham G, et al, "Detection and Acceptance of Demand-Responsive Lighting in Offices with and without Daylight," Leukos, Vol. 4, No. 3, January 2008, pp 139-156.

Rubinstein, F., S. Kiliccote (2007). “Demand Responsive Lighting: A Scoping Study”, LBNL62226.

Tretheway, D. (2009). "Straw Proposal for Participation of Non-Generator Resources in California ISO Ancillary Services Markets".

U.S. Department of Energy (2009). Buildings Energy Data Book.

U.S. Energy Information Administration (2003). “Commercial Buildings Energy Consumption Survey (CBECS)".

Watson, D., Motegi, N. (2005). "Lab tests of the Demand response automation server under various throughput loading conditions". LBNL 2005 


\subsection{Glossary}

$\begin{array}{ll}\text { A/D } & \text { Analog to Digital } \\ \text { A/S } & \text { Ancillary Services } \\ \text { CAISO } & \text { California Independent System Operator } \\ \text { CBECS } & \text { Commercial Building Energy Consumption Survey } \\ \text { CPP } & \text { Critical Peak Pricing } \\ \text { DALI } & \text { Digital Addressable Lighting Interface } \\ \text { DR } & \text { Demand Response } \\ \text { DRAS } & \text { Demand Response Automation Server } \\ \text { EIA } & \text { Energy Information Agency } \\ \text { LBNL } & \text { Lawrence Berkeley National Laboratory } \\ \text { NRC } & \text { National Research Council }\end{array}$

